\section{Setting sail for history}

A small budget and big dreams make for a heady mix. But solar-sail pioneer Lou Friedman is ready for anything as spacecraft Cosmos 1 prepares to take on the Sun and the space agencies. Tony Reichhardt reports.

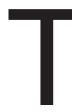
his is a story about patience. Not just one man's patience, although Lou Friedman has waited half his life to get a solar sail into space. Futurists, too, have been dreaming about this technology for nearly a century and have yet to see it demonstrated. In April, if all goes to plan, a 600-square-metre Mylar sail called Cosmos 1 , which looks more like a windmill than a starship, will prove that a spacecraft can be propelled by sunlight alone.

First, though, it will have to be launched into orbit on a converted missile from a Russian nuclear submarine in the Barents Sea. Cosmos 1 is privately funded by the Planetary Society, a US space-advocacy group based in Pasadena, California, which Friedman heads, but it was built in Moscow by the ex-Soviet aerospace company NPO Lavochkin.

After the sail reaches its initial 800-kilometre orbit and unfolds its eight triangular vanes, ground controllers will tilt the vanes like sailors feeling for the wind. A slight boost to the spacecraft's orbit is all they need to demonstrate propulsion by light pressure. It may take a few days, but the Cosmos team won't mind waiting.

Solar sails are not for people in a hurry. They accelerate almost imperceptibly at first, as photons of light bounce off their enormous reflective surface, imparting momentum. But, unlike conventional rockets, they can accelerate continuously, and keep accelerating as long as the Sun is shining, without needing a drop of fuel.

\section{Light speed}

After one day, the velocity increase for an interplanetary sail would be a modest 160 kilometres per hour. After 100 days, the sail would be moving at $16,000 \mathrm{~km} \mathrm{~h}^{-1}$. In three years it would be travelling 160,000 $\mathrm{km} \mathrm{h}^{-1}$, three times faster than the Voyager spacecraft now exiting the Solar System, and fast enough to reach Pluto in less than five years - half the time the NASA New Horizons mission will take to reach Pluto.
This is why science fiction writers love solar sails - as do aerospace engineers, at least in theory. In the 1970s, Friedman was a project manager at NASA's Jet Propulsion Laboratory (JPL) in Pasadena, California, where he led the conceptual design of a US mission to Halley's Comet, using a gigantic $640,000-\mathrm{m}^{2}$ sail. The idea was shot down by NASA management as too risky. "In retrospect it was too audacious," Friedman admits today, "and the schedule was unrealistic."

After leaving JPL, Friedman co-founded the Planetary Society with scientists Carl Sagan and Bruce Murray in 1980 . While pushing the society's agenda of international space cooperation, he built solid friendships and working relationships with Russian space scientists and engineers, at a time when such relations were viewed with suspicion. Later, it made economic and technical sense for the Planetary Society to turn to Russia for help on the solar-sail project. The missile launch was a bargain; NPO Lavochkin was already working on inflatable spacecraft (the masts that hold the Cosmos 1 sail must inflate in space), and Russian interest in solar sails dates back to the visionary Konstantin Tsiolkovsky, who wrote about them as early as 1921 .

Right now, Friedman is trying to balance his excitement at getting this far, with more realistic expectations. The project's tiny US $\$ 4$-million budget ("NASA would spend almost that much on the paper studies," he says) has meant cutting corners on certain materials and the number of design reviews. But the
"No one knows exactly how stable it will be, or whether it will twist and curl on itself like a flimsy kite in a strong wind." team is made of "capable, experienced people" who have tried to anticipate everything that could go wrong. After one technical review in Moscow, recalls Friedman, a Russian consultant gave Cosmos 1 as much as a $70 \%$ chance of succeeding. "I said: 'You give it 70? Man, I'll take that!'”

Unfortunately, the team missed its chance to test the sail's deployment on a suborbital launch in 2001, when the spacecraft failed to separate from its rocket, and both were lost at sea. Instead of repeating this short flight, Friedman and his colleagues decided to go straight to orbit for their next try.

Although NASA wouldn't approach a high-risk project in this way, the agency will be cheering Cosmos from the sidelines, says Tim Van Sant of the Goddard Space Flight Center in Maryland. Van Sant manages technology development for NASA's Sun-Earth Connection 


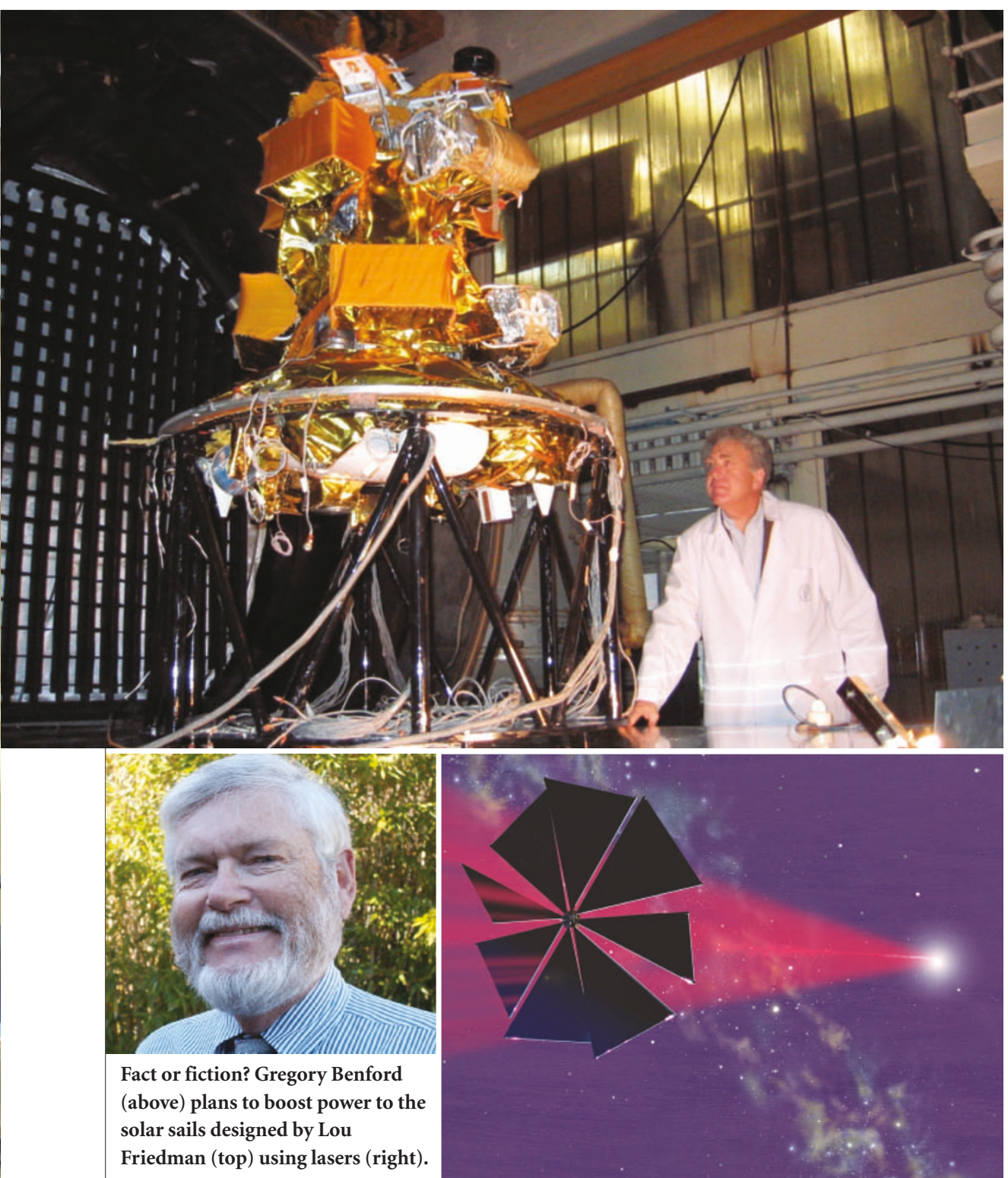

programme. His office has long contemplated solar sails for missions that cannot be done with conventional propulsion. Placing a spacecraft in a close polar orbit around the Sun, for example, requires enormous amounts of rocket fuel to fight the inward pull of solar gravity. Solar sails would act as natural brakes, and would never run out of fuel.

\section{Catching the breeze}

But there is a big gap between dreaming and doing. Most plans for solar sails have never got anywhere near the Sun. In 1992 there was talk of an international solar-sailing regatta to celebrate the 500th anniversary of Columbus's voyage to America. Groups including the Pasadena-based World Space Foundation got as far as building and testing sails on the ground, using a mix of professional and amateur labour, but their money dried up. More recently, a Texas-based group called Team Encounter announced plans to attach paying customers' messages, drawings, photographs and DNA samples to a sail and send it off into interstellar space. None of these projects has come close to launching.

In terms of flight experience with solar sails, Japan is the world leader until Cosmos 1 launches. Last August the Japanese Aerospace Exploration Agency (JAXA) conducted a brief suborbital test on a sounding rocket, during which two 10-m sails unfurled from a mast to form a pinwheel shape. In May the agency will test a 20 -m sail suspended from a scientific balloon at an altitude of $35 \mathrm{~km}$.

JAXA's ultimate goal is a hybrid propulsion system combining solar sailing with ion-drive engines. One proposed JAXA mission would combine a $50-\mathrm{m}$ solar sail with an ion drive to place a probe in orbit around Jupiter's poles and fly past several asteroids.

No one, though, has got as close to orbit as Friedman is today. Even if the sail deploys on cue, he's not sure when he should celebrate. "It could be a very tenuous success," he says, as the mission team tries to control its sail and push it into a higher orbit. Of the many technical challenges facing solar sails, Fried- man counts dynamics as perhaps the most vexing. No one knows exactly how stable it will be, or whether it will twist and curl on itself like a flimsy kite in a strong wind.

If Cosmos 1 reaches a higher orbit and meets all its other mission objectives, it will be used for one last, futuristic experiment. University of California physicist and science fiction writer Gregory Benford, along with his brother James, president of Microwave Sciences in Lafayette, California, will aim a 450kilowatt microwave beam from a radio antenna in the Mojave Desert towards the sail. They hope the beam will give an extra push to the sail. Someday, that method may be used to propel gossamer sails more quickly to other planets, and perhaps even other stars.

\section{On the right tack}

A successful Cosmos 1 mission would give a gentle push to solar-sail projects within the space agencies. The earliest NASA could fly a solar sail is 2009 on the Space Technology 9 demonstration mission, although other technologies will be competing for that flight.

Among NASA's long-term solar-sail proposals are the Particle Acceleration Solar Orbiter, which would orbit close enough to the Sun to keep a steady gaze on active solar regions, and a Solar Polar Imager for studying the Sun's higher latitudes. NASA and the National Oceanic and Atmospheric Administration would also like to put weather stations in stable orbits between Earth and the Sun to give advance warning of sunstorms. These would need sails three to five times bigger than Cosmos 1 .

The European Space Agency is interested in solar sails too, for reasons similar to NASA's - to place an orbiter around the poles of the Sun. The agency is also studying another mission concept called Earthguard to visit near-Earth asteroids.

Although no solar-sail missions have yet been approved, Van Sant is spending about $\$ 10$ million a year laying the technological groundwork. This year two pioneers of solarsail development, L'Garde of Tustin, California, and ABLE Engineering of Goleta, California, will test different designs for 20-m sails in a giant vacuum chamber at NASA's Plum Brook facility in Ohio.

ABLE's sail is made of an extremely thin new polymer called CP-1, only 2.5 micrometres thick - half as thick as the aluminized Mylar on Cosmos 1. "If you sneeze, you'll send this stuff across the table," says Van Sant. Thinner and lighter is better when it comes to solar sails, but flimsy films are also more prone to tearing. Even the reinforced sails of Cosmos 1 won't last forever: within a month of launch they will begin to degrade in the harsh sunlight. But the short flight should be long enough to demonstrate the principle of solar sailing, and if successful will open the heavens to other solar-powered craft.

Tony Reichhardt writes for Nature from Washington DC. 